\title{
Research on Quality Evaluation System of Practical Training for Engineering Majors in Local Agricultural Universities
}

\author{
Hua Liu \\ College of Engineering and Technology \\ Tianjin Agricultural University \\ Tianjin, China \\ 41599386@qq.com \\ Weiyu Zhang \\ College of Engineering and Technology \\ Tianjin Agricultural University \\ Tianjin, China \\ 525156985@qq.com
}

\author{
Yong Wei \\ College of Engineering and Technology \\ Tianjin Agricultural University \\ Tianjin, China \\ 595183963@qq.com \\ Yu Shi \\ College of Engineering and Technology \\ Tianjin Agricultural University \\ Tianjin, China \\ syych83@tjau.edu.cn
}

\begin{abstract}
Practice training is an important part of the training program for engineering professionals in local agricultural universities. The monitoring and evaluation of teaching quality is very important. On the basis of a correct understanding of the basic problems of quality evaluation in the practical training link of engineering practice, it follows the principles of combining comprehensiveness and effectiveness, combining objective and operational, combining static and dynamic characteristics, and from the four major aspects of practice te aching management, base construction, content design and implementation, quality assessment and feedback. On the other hand, the quality index of each observation point is arranged reasonably, the corresponding quality evaluation standard is formulated, and a comprehensive and general practice training link quality evaluation system is constructed.
\end{abstract}

Keywords-Engineering Major, Practice Training, Quality Evaluation System, Agricultural Universities

\section{INTRODUCTION}

As a local higher agricultural college, Tianjin Agricultural University has always paid attention to the talent training plan to fully reflect the talent cultivation concept of "high quality, strong ability and heavy application". On the one hand, the establishment of the theoretical course and the practice link must be closely linked; On the other hand, the practice teaching of practice training must be closely connected with the production practice. [1]. It must be in accordance with the service as the purpose, the employment orientation, the improvement of the quality as the core, and the enhancement of the special color as the focus of the higher vocational education. We need to make full use of theory and apply it to our needs. Practice training teaching is more intuitionistic, comprehensive and practical than classroom theory teaching. It plays an important and irreplaceable role in strengthening

1. Major Education Reform Bidding Project of Tianjin Agricultural University (2017-B-00).

2. Key Projects of Tianjin Education Committee (171006101C) quality education and training innovation ability of engineering students [2]. Reasonable and scientific practice teaching quality evaluation system has become an important link in the construction and improvement of practice training teaching system. It is helpful to promote the formation of good quality monitoring mechanism for professional education, promote the construction and development of engineering major and improve the quality of talent training. This paper takes the measurement and control technology and instrumentation specialty of Engineering Technology Institute as an example [3].

\section{The Basic Problems in Constructing Practical TEaching Quality Evaluation System}

\section{A. The embodiment of the quality of internship training}

The correct quality concept is directly related to the social recognition of higher education and its own healthy development. Its quality is mainly reflected in two levels: First, the individual's 'high quality", based on the undergraduate level of local agricultural colleges and its academic requirements, the engineering professional practice in Tianjin Agricultural University, College of Engineering and Technology, including training session setting, teacher level, etc. must meet the students' needs for study and employment and the needs of sustainable development; Second, the students' "strong ability, heavy application", are reflected from the teaching content, syllabus and curriculum of the internship training session. The teaching process must meet the needs of employers and the needs of local universities for their own sustainable development. Therefore, in order to meet the dual needs of society and individuals, we must start from the characteristics and characteristics of internship training, curriculum development, teaching process and resource 
management, and pay attention to the monitoring and evaluation of education and teaching quality under natural conditions [4].

\section{B. Basis for quality monitoring and evaluation of internship training}

Internship training is special operation training for students in practical or simulated professional environments in accordance with the standards of talent training programs and training courses, so that they can acquire the basic operational skills needed for production, management and service of firstline positions. Professional skills and comprehensive skills to improve students' professional quality, professional ability and employability are important teaching links combining students' theory and practice, and an important way to cultivate applied talents. The practical teaching system of this goal is realized by the organic integration of basic skills internship training, professional skills internship training, and comprehensive training.

\section{Basic Principles of Quality EVAluation of INTERNShIP TRAINING}

A comprehensive evaluation of the quality of internship training is a complex process. The evaluation includes management monitoring and evaluation, identification of evaluation personnel, identification of problems to be solved, design evaluation plans, collection and analysis information, and report evaluation. Therefore, to construct a complete evaluation system for the quality of internship training, it must be comprehensively considered, covering all aspects of internship training and teaching and learning, focusing on comprehensive monitoring and key evaluation, general evaluation and characteristic evaluation, process monitoring. Complementary combination with outcome evaluation to determine multi-level indicators, multi-stage indicators, main observation points and assessment criteria [5].

To construct an internship training teaching quality evaluation system, it is necessary to follow and conform to the education and teaching rules of engineering majors in Tianjin higher agricultural colleges, and to have the operability in daily natural education and teaching activities. The purpose of the evaluation is not to simply rank the rankings and the pros and cons, but to guide and encourage all internship training courses to develop in the right direction and goals. The definition of indicators in the evaluation should be clear, and the evaluation criteria should be objective and comprehensive, in line with the overall objectives of the practical training of engineering majors. The development of the evaluation index system should not only be able to measure the quality of the internship training, but also be simple and easy to implement in the evaluation process.

As a complete indicator system, its content should be relatively stable. However, education and teaching is a dynamic process, so the monitoring and evaluation of its quality should also be dynamic, and must be constantly adjusted and improved according to changes in internal and external conditions and factors. On the one hand, the evaluation criteria of some indicators will change with the changes of internal and external conditions affecting local universities; on the other hand, the evaluation criteria of schools in different regions and different natures are not the same. In this regard, in the design of evaluation indicators, we must fully consider the environmental factors, regional factors and the type and characteristics of the school, and make a combination of static and dynamic [6].

\section{Design of Teaching Quality Evaluation System}

We have established the overall framework of quality evaluation system for the practical training link of engineering practice in Tianjin local higher agricultural colleges and universities. On the basis of 'basic + specialty + application + comprehensive" module progressive "BSAI" practice teaching mode, we explore the core of improving students' ability to solve complex engineering problems. The practice of teaching content, implementation methods and assessment system, in line with the principle of 'taking the elephant in the money, the outside circle", that is, the copper money is in a circular form, the "circle" symbolizes adaptation, and "Fang" represents the norm. The quality evaluation system should be a highly standardized framework with extensive adaptability. The internal standardization mainly reflects from four aspects: first, it is the standardization of the teaching management in practice training link; two, it is the rationality of the practice training base; three, the practical training content is scientific; four, it is the diversity of practice training assessment methods.

\section{A. Evaluation index and standard of teaching quality in practical training}

The key points of the practice teaching quality evaluation system are the syllabus of basic skill practice training, professional skill practice training, comprehensive training and so on, the practice teaching plan, the student practice training manual, the practical training inspection index, the quantitative evaluation index of practice training management, and the practical training guidance in the school and outside the school. The teaching quality evaluation system should be comprehensive and overall. Specifically, the above four aspects include first level indicators, refined two level indicators and corresponding evaluation criteria. As is shown in Fig. 1.

The comprehensive evaluation function permeates in the whole practice training evaluation process, maximizes the elimination of evaluation error, and improves the improvement in time, and truly promotes teaching and learning. 


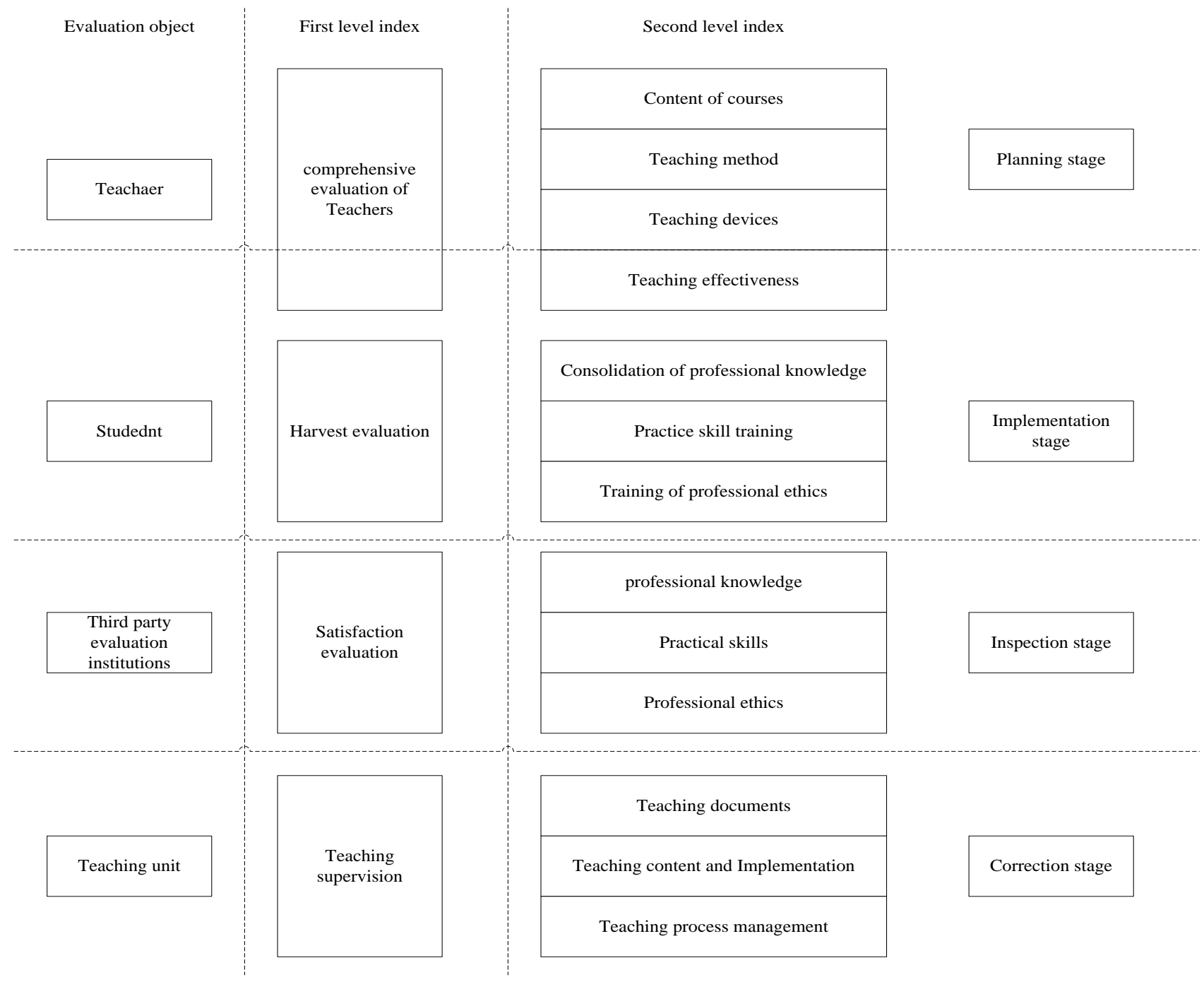

Fig. 1. Evaluation Index and Standard of Teaching Quality in Practical Training

\section{B. Evaluation system of intern practice training}

Practical training in schools refers to the verification experiments, basic skills training, professional basic training and comprehensive training completed in the school training base. Intern practice is to promote knowledge learning through ability training, transform theoretical knowledge into practical skills, and improve students' professional knowledge, professional skills and practical ability.

According to the characteristics of internship training and the ability training as the standard, we divide the practical training into two basic skills training and comprehensive training. The first grade index of basic skill training evaluation is the practical training attitude, the training process and the practical training effect. The evaluation content of the practical training attitude is the attendance, the compliance of the discipline, the professional or the professional habits. The training process is evaluated by the students to complete the basic skills training. The training effect is the comprehensive test or examination. We should evaluate students' ability to flexibly use their knowledge and skills to complete training projects.

\section{Evaluation system of extern practice training}

Externship refers to productive teaching practice and postpractice in off campus training bases (enterprises). Through the practice of enterprise production, it aims to let students experience the actual production process of the enterprise in the "quasi job", understand and familiarity with the requirements of the job of the enterprise, cultivate the consciousness of the students, the team spirit of mutual assistance and cooperation, and the ability to discover and solve the problems, and enhance the ability of the students' job practice and improve the ability of the students' post. The comprehensive quality of students can shorten the gap between students' graduation and society.

During the internship of the students in the off campus training base, the students play two roles in the "quasi job" position. Therefore, when evaluating students' extracurricular practice, we should combine the two, and adopt qualitative 
and quantitative methods to evaluate students. Through the investigation of the performance evaluation index of the employees, the professional skills and work attitude are selected as the first level index, and the students' professional knowledge and ability, the ability to solve the problems, the quality and efficiency of completing the work task, the teamwork ability, the work ability and the strain ability, the work initiative and the sense of responsibility, the work attendance rate and the work rate are also selected. A comprehensive assessment of punctuality and practice summary is carried out, and a quantitative index system is established. The evaluation and evaluation of students' practice quality mainly consist of four aspects: self-evaluation, school evaluation, enterprise evaluation and practice summary. Their respective weights are 20\%, 30\%, 30\% and $20 \%$ respectively. Each item is calculated by 100 points, and the forth part is the overall achievement of the students' post internship.

\section{Implementation Effect of The Evaluation System}

Through the reform and implementation of the practice training quality evaluation system, the traditional evaluation content theory is changed, the evaluation subject, the evaluation method and the evaluation standard are single, the quantitative evaluation, the light qualitative evaluation, the heavy end evaluation and the light process evaluation; the evaluation content is attached to the teaching material, the evaluation method is simple, lack of scientific and effective. The question of sex. The practice training evaluation can objectively and comprehensively reflect the students' real learning situation and the goal of the application type engineering education to the talents training promote the students' growth and encourage the students to study, and improve the quality of practice training and the quality of the training of the school talents. In the questionnaire survey of curriculum assessment and evaluation reform, $91.67 \%$ of the students think that the assessment content of the practice training evaluation system can reflect the students' learning attitude and ability level, and the way of assessment is reasonable.

The system pays attention to the evaluation of the students' learning process, pays attention to the progress and changes of the students in the process of learning, makes the problems encountered in the learning process can be solved in time, exerts the timeliness and motivation of the learning evaluation, strengthens the connection between teachers and students, and enables the students to solve their own shortcomings and progress in time, and let more. The success of students reflects the joy of success and the pleasure of learning, thus promoting students' autonomous learning and all-round development.

As is shown in Fig. 2, in the past three years, the recognition of students, teachers and the three party has increased year by year under the quality evaluation system of practical training.

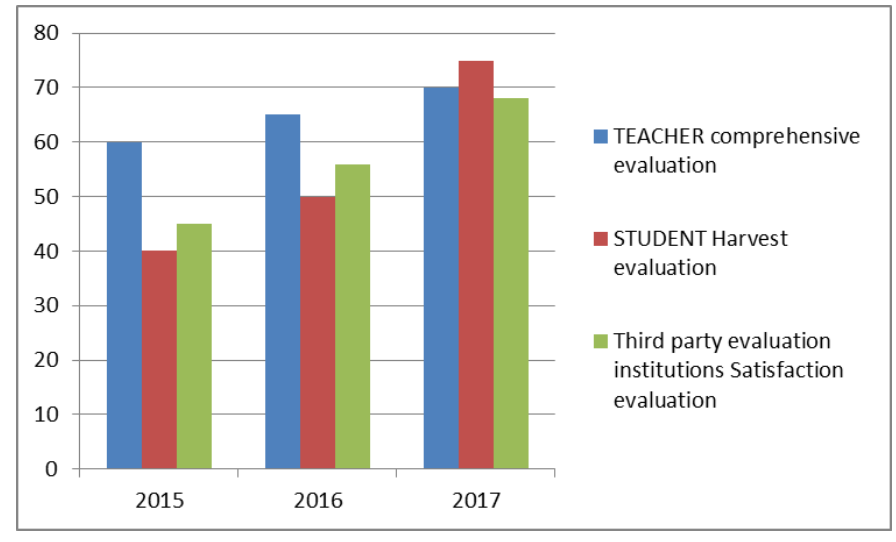

Fig. 2. Comparison of the Past Three Years

\section{CONCLUSIONS}

The comprehensive and multi angle practice teaching quality evaluation system has strengthened the students' responsibility, promoted the students to "learn from me" to "I want to learn", improved the students' ability to study independently, aroused the students' initiative and enthusiasm in the experiment process, and trained the students to find problems, analyze problems and solve problems. The ability to improve their ability to innovate. At the same time, the evaluation system is continuously optimized on the basis of planning, implementation, summary, rectification and evaluation, so as to adapt to the current social needs for the students of the local agricultural colleges and universities to realize the training of talents and the rational allocation of resources.

\section{ACKNOWLEDGMENT}

This work was financially supported by the Major Education Reform Bidding Project of Tianjin Agricultural University (2017-B-00) and Key Projects of Tianjin Education Committee (171006101C).

\section{REFERENCES}

[1] Zhang Rui, Xu Peng, Fang Mingfeng, Investigation into the Assessment of Students'Abilities in Local Comprehensive Universities Based on Procedural and Developmental Assessment and Multip le Evaluations [J] Journal of Chongqing University of Technology (Social Science). 2014,28(4):129-133. In Chinese

[2] Mei Yingjun. Research of Teachers Reform of Assessment of College Major Courses [J]. JOURNAL OF NINGBO UNIVERSITY (EDUCATION EDITION). 2009. 31(6):25-27+38. In Chinese

[3] Cao Aifeng. Research on the Undergraduate Training Model of Nanjing University (1984-1996) [D]. Nanjing University, 2013.

[4] Xiao Wan, Liu Dameng, Deng Yanxi. Research on Big Data Index System of Professingal Teaching Quality [J]. CHINESE GEOLOGICAL EDUCATION, 2018,02:39-43. In Chinese

[5] Li Shaozhong, Ouyang Kui. Research on Evaluation Index System Construction and Evaluation Method of the Quality of Higher Vocational Students'Intership [J]. Experimental Technology and Management. 2014,31(9):155-157. In Chinese

[6] Zhu Xinzhuo, Yan Rui, Liu Yanyue. Research on Educational Quality Based on Process and its Evaluaion [J]. Journal of Higher Education. 2015,36(5):78-85. In Chinese 